\title{
DEVELOPMENT AND EVALUATION OF A GARLIC"Allium sativum" PEELING PROTOTYPE
}

\author{
Badr, M. M.*
}

\section{ABSTRACT}

The aim of the present study is to develop and evaluate garlic peeling prototype by centrifugation and friction to be used in home and small processing units as restaurants and hotels. Experiments were carried out with two varieties of garlic cloves, three numbers of fins (one fin, two fins and three fins) and three rotating disk speed (1600, 1800 and 2000 r.p.m). Results showed that the highest values of productivity were 4.00 and $1.47 \mathrm{~kg} / \mathrm{h}$ for red garlic " $R G$ " and white "WG" garlic respectively at disk speed of 1600 r.p.m and number of fins of 1 fin, the lowest values of cloves damage percentage were $2.26 \%$ and $6.92 \%$ for " $R G$ " and "WG" garlic respectively for disk speed of 1600 r.p.m and fins number of 3 fin and the lowest values of unpeeled cloves percentage were $5.29 \%$ and $19.20 \%$ for " $R G$ " and "WG" garlic respectively for disk speed of 2000 r.p.m and fins number of lfin. Comparing peeling efficiency for the same operational conditions clear that the peeling efficiency for " $R G^{\prime \prime}$ garlic was $85.1 \%$ compared to $57.6 \%$ for "WG" garlic. The dimensional analysis was reasonably accepted for predicting the peeling efficiency with coefficient of determination 0.978 that helps in producing large scale peeling machines of garlic cloves.

\section{INTRODUCTION}

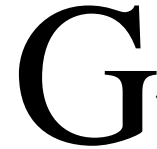
arlic products are being promoted in the form of volatile oils, juices, extracts in liquid and dried forms and macerates for utilization in pharmaceuticals and food preservation. Series of garlic juice biological benefits have been mainly attributed to the antioxidative activity. They are antiatherosclerotic, antihypertensive, antimicrobial, anticancer, immunomodulation, and radioprotection (Zeng et al., 2008). For garlic, dry peeling was better than wet peeling in reducing microbial population and preserving ascorbic acid content. Removal of the root, a potential source for microbial contamination, reduced microbial load of garlic and this may be applicable to other minimally processed vegetable (Park et al., 1998).

*Lecturer of Ag. Products Porocess Eng. Dept., Fac. of Ag. Eng., Al-Azhar Univ., Cairo, Egypt. 
The quality of processed fruits and vegetables is highly dependent on the peeling stage. Poor peeling management leads to expensive finished products due to high peeling losses and low quality of finished produce. The ideal peeling method aims to remove the peel with high efficiency and low peeling losses as normally desirable (expected losses) (Somsen et al., 2004).

There are many methods for peeling such as manual, mechanical, chemical and thermal peeling. The selected method depends upon the type and variety of products to be processed the capacity of industrial plant and the efficiency and losses of the method.

Emadi et al. (2007) stated that, mechanical peeling of fruits and vegetables are mostly using either abrasive tools or knife and blades. Combining the basic functions of these two types of peeler tools led to the development of a new innovative tool named the abrasive-cutter brush. The new tool can utilize the benefits of the two mentioned peeling tools. The production and effect of peeling using abrasive cutter brush on Jap variety of pumpkin as a case study was examined. The experimental studies showed high flexibility of abrasive-cutter brush could provide easy access to different uneven areas of the produce. The cutting action caused effective peeling while the abrasive action showed higher production compared with the existing tools.

The aim of the present study is to develop and evaluate garlic peeling unit to be used in home and small processing units as restaurants and hotels that could be achieved by:

- Studying some physical properties of garlic cloves.

- Studying engineering aspects affecting constructing and manufacturing for the garlic peeling prototype parts.

- Evaluation of the garlic peeling prototype for higher peeling efficiency and quality as affected by different operational parameters.

- Cost analysis to determine the final peeling cost at different operational parameters.

\section{2-MATERIALS AND METHODS}

A prototype of the garlic cloves peeling is constructed and tested at the workshop of the Agricultural Engineering Faculty, Al-Azhar University, Nasr City, Cairo. 


\subsection{MATERIALS:}

\section{- Raw Materials:}

Two garlic varieties "Allium sativum" (red garlic "RG" صينى and white garlic "WG"بلدى) were obtained from some farms in the villages of EL Mahalla El Kubra, Gharbia Governorate, Egypt, after three weeks from harvest. Prior the peeling, samples of garlic fruits were separated to cloves as in Fig. (1).

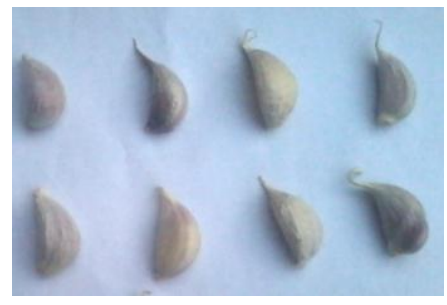

(a)

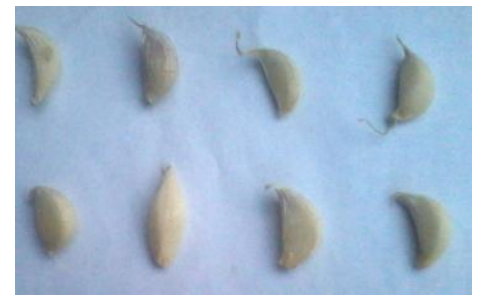

(b)

Fig (1): Red "RG" (a) and white "WG" (b) garlic cloves.

\section{- Garlic peeling prototype construction:}

A prototype, is manufactured for peeling garlic cloves, is consisted of, peeling chamber, rotating disk and source of power. The photograph of peeling prototype is shown in Fig. (2). The peeling prototype was consisted of:

- Peeling chamber: The peeling chamber is vertical cylinder of PVC, its dimensions of $102 \mathrm{~mm}$ inner diameter, $110 \mathrm{~mm}$ high and $4 \mathrm{~mm}$ thickness. Three fins of wood having dimensions of 70 length $\times 16$ width $\times 10$ thickness $\mathrm{mm}$ are fixed on the inner surface of the peeling chamber parallel to the longitudinal axis. The peeling chamber is fixed on a rectangular base of wood (250 length $\times 150$ width $\mathrm{mm}$ ) with thickness $25 \mathrm{~mm}$.

- rotating disk: The rotating disk of wood with diameter $100 \mathrm{~mm}$ and its thickness $12 \mathrm{~mm}$ is fixed in the bottom of the peeling chamber by metal axis (10 mm diameter and $75 \mathrm{~mm}$ length) passes through the wood base and connected with power source. The top surface of the disk contains protrusions to force the garlic cloves to circular motion. The elevation and plan of peeling chamber and rotating disk are shown in Fig. (3).

The garlic cloves are move inside the peeling chamber by the rotating disk, resulting in friction between the garlic cloves and fins, leading to the separation of peel. 


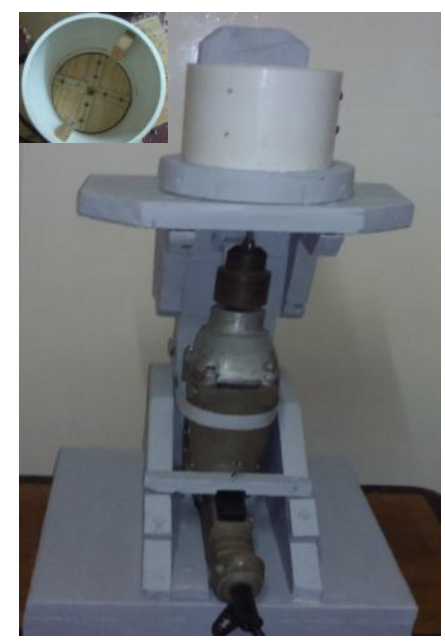

Fig. (2): Photograph of peeling prototype.
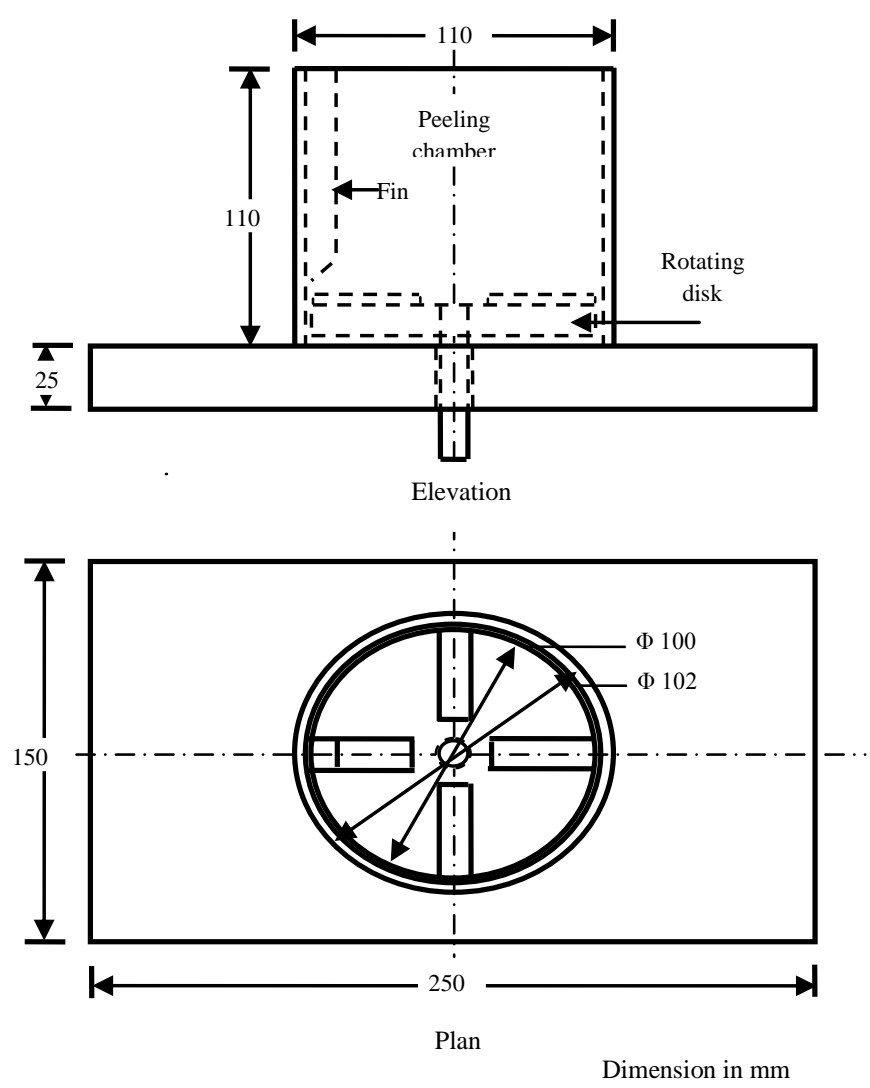

Fig (3): The elevation and plan of peeling chamber. 
-The source of power: The power source used was electrical motor (various speeds) directly joined to a metal axis of rotating disk, of 0 2500 r.p.m, $220-230 \mathrm{~V}, 50-60 \mathrm{~Hz}$ and $810 \mathrm{~W}$, made in china.

\section{-Measuring instruments:}

\section{- Digital caliper:}

A digital caliper (accuracy of $0.01 \mathrm{~mm}$ ) made in China, was used for measuring the garlic cloves dimensions.

\section{-Electrical balance:}

Weight of samples were measured by a Sartorius electrical balance made in Japan, (HR- 200, max $210 \mathrm{~g}$ ) having accuracy of (0.0001 g).

\section{-Electric oven:}

The moisture content of garlic cloves was evaluated by oven dried (VENTICELL55 type, 230V, 50/60 Hz, 1250W, $250^{\circ} \mathrm{C}$ Max. temperature).

\section{-Digital photo tachometer:}

A digital photo tachometer was used to measure the rotational speed r.p.m of the rotating disk. The specifications of tachometer are as follows: range of the measurement is 2.5 to 99999 r.p.m and its accuracy is 0.1 r.p.m through the speed 2.5 to 999.9 r.p.m and 1 r.p.m over 1000 r.p.m.

\section{-Stop watch:}

Stop watch (accuracy $1 \mathrm{sec}$.) was used to record the peeling time.

\section{- A digital AVO meter:}

A digital AVO meter was used to measure the consumption of electrical current "A", the specifications of device are as follows: accuracy of device 0.01 , rang the measurement $(0-40 \mathrm{~A})$ and the device made in china.

\subsection{METHODS:}

\section{- The experiments procedure:}

Experiments were carried out on 100 gram samples of two varieties of garlic cloves (red garlic "RG" and white garlic "WG") with three replicates. In order to study peeling of garlic cloves and to describe the two previous varieties and to set a database for future processing, some physical properties of garlic cloves were studied and that affecting the prototype design were also measured such as: length "L" (mm), width "d", thickness "T" (mm), geometric diameter " $\mathrm{D}_{\mathrm{g}}$ " (mm), arithmetic diameter " $\mathrm{D}_{\mathrm{a}}$ " $(\mathrm{mm})$, volume "V" $\left(\mathrm{mm}^{3}\right)$, flat surface area " $\mathrm{A}_{\mathrm{f}}$ " $\left(\mathrm{mm}^{2}\right)$, 
bulk density " $\rho_{\mathrm{b}}$ " $\left(\mathrm{kg} / \mathrm{m}^{3}\right)$ mass of 100-cloves $(\mathrm{g})$, moisture content "M.C" $(\%)$ and peel percentage " $\mathrm{p}_{\mathrm{p}}$ " (\%).

Experiments were carried out with three numbers of fins (one fin, two fins and three fins) and three rotating disk speed (1600, 1800 and 2000 r.p.m) with "RG" and "WG" garlic cloves respectively. Productivity "P" (kg/h), peeling efficiency " $\eta_{\mathrm{p}}$ " (\%), damaged garlic cloves " $\mathrm{d}_{\mathrm{c}}$ " (\%) and unpeeled garlic cloves "U" (\%) were calculated for all experiments at different the previous variable.

Dimensional analysis has been done for the optimal selected system to predict suitable formula for large scale peeling machines.

\section{- Calculations:}

\section{-Garlic cloves dimension:}

Characteristic dimensions as length, width, and thickness (mm) were measured by using digital dial caliper. These physical characteristics can be utilized effectively in design and development of the peeling prototype and affecting their peeling operations and in analyzing the behavior of product in handling, sieving and peeling processes. The following relations can be used for calculating the geometric diameter " $\mathrm{D}_{\mathrm{g}}$ " $(\mathrm{mm})$ and arithmetic diameter " $\mathrm{D}_{\mathrm{a}}$ " (mm) according to (Matthews, 1991) as:

$$
\begin{aligned}
& D_{g}=(L . W . T)^{\frac{1}{3}} \mathrm{~mm} \\
& D_{a}=\left(\frac{L+W+T}{3}\right) \mathrm{mm}
\end{aligned}
$$

were: $\boldsymbol{L}$ : Length, (mm), $\boldsymbol{W}$ : Width, (mm) and $\boldsymbol{T}$ : Thickness, (mm).

\section{-Garlic clove surface area:}

The following relation was used for calculating the flat surface area $\left(A_{f}\right)$ in $\left(\mathrm{mm}^{2}\right)$, according to (Matthews, 1991) as:

$$
A_{f}=\frac{\pi}{4}(L . W) \mathrm{mm}^{2}
$$

\section{-Bulk density:}

The bulk density was calculated for the cloves by dividing the mass of quantity of cloves on its volume, which was measured by using a graduated cylinder Matthews (1991) as: 
PROCESS ENGINEERING

$$
\rho_{b}=M_{b} / V_{b}
$$

Where: $\rho_{p}$ : Bulk density of garlic cloves $\left(\mathrm{kg} / \mathrm{m}^{3}\right), \boldsymbol{M}_{\boldsymbol{b}}$ : Mass of the quantity of garlic cloves, $(\mathrm{kg})$ and $V_{b}$ : Volume of the quantity of garlic cloves, $\left(\mathrm{m}^{3}\right)$.

- Moisture content:

The moisture content of cloves was determined using oven method according to the procedure described in the standard methods (ASAE, 1994); oven dried at $105^{\circ} \mathrm{C}$ for 24 hours, moisture content was calculated on wet and dry basis as follows:

-Moisture content "M.C" wet basis, (\%):

$$
M . C=\frac{W_{m}}{W_{m}+W_{d}} \times 100
$$

where: $W_{m}$ : Mass of moisture in sample, $(\mathrm{g})$ and $W_{d}$ : Mass of bone-dry material, $(\mathrm{g})$.

\section{-Peel percentage " $p_{p}$ ":}

The percentage (\%) of peel in garlic cloves was calculated as follows:

$$
p_{p}=(M P / M T G) \times 100
$$

where: $\boldsymbol{M P}$ : mass of the peel in garlic clove sample and $\boldsymbol{M T G}$ : mass of total garlic clove sample.

-Evaluation of the performance:

-Productivity:

Machine productivity "P" (kg/h) was calculated as follows:

$$
P=w_{1} / \theta
$$

where: $\boldsymbol{w}_{1}$ : mass of peeled garlic cloves $(\mathrm{kg})$ and $\boldsymbol{\theta}$ : the time consumed in peeling operation $(\mathrm{h})$.

\section{-Peeling efficiency:}

The following relation was used for calculating peeling efficiency " $\boldsymbol{\eta}_{\boldsymbol{p}}$ (\%) according to Mudgal and Champawat (2011) as:

$$
\eta_{p}=\frac{w_{1}}{w} \times 100
$$

where: $\boldsymbol{w}_{1}$ : mass of peeled garlic cloves $(\mathrm{g})$ and $\boldsymbol{w}$ : the total mass of garlic cloves sample (g). 


\section{- Unpeeled and damaged cloves percentage:}

The unpeeled cloves percentage " $\boldsymbol{U}_{\boldsymbol{c}}$ " $(\%)$ and the damaged cloves percentages $" \boldsymbol{D}_{\boldsymbol{c}}$ " (\%) were calculated as the follows:

$$
\begin{aligned}
& U_{c}=\left(w_{2} / w\right) \times 100 \\
& D_{c}=\left(w_{3} / w\right) \times 100
\end{aligned}
$$

where: $\boldsymbol{w}_{2}$ : mass of unpeeled cloves $(\mathrm{g})$ and $\boldsymbol{w}_{3}$ : mass of peeled but damaged cloves $(\mathrm{g})$.

\section{-Analytical study:}

Dimensional analysis technique was used to develop a prediction model for the optimal selected garlic cloves peeling system based on the

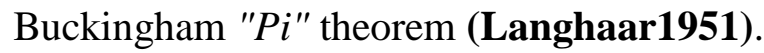

Six variables are pertinent for the peeling machine prototype and they are presented in Table (1). Basic dimensions are mass (M), length (L) and time $(\theta)$. The peeling efficiency required can be expressed as a function of the other five variables, $\eta_{p=} f(P, N, v, F, n)$.

Table (1): Variables used in the dimensional analysis.

\begin{tabular}{|l|c|c|c|c|}
\hline No. & Symbol & Description & Dimension & Units \\
\hline 1 & $\boldsymbol{\eta}_{\boldsymbol{p}}$ & Peeling efficiency & Dimensionless & --- \\
\hline $\mathbf{2}$ & $\boldsymbol{P}$ & Prototype productivity & $\mathrm{MT}^{-1}$ & $\mathrm{~kg} / \mathrm{s}$ \\
\hline $\mathbf{3}$ & $\boldsymbol{N}$ & Rotating disk speed & $\mathrm{T}^{-1}$ & $\mathrm{~s}^{-1}$ \\
\hline $\mathbf{4}$ & $\boldsymbol{V}$ & Volume of sample & $\mathrm{L}^{3}$ & $\mathrm{~m}^{3}$ \\
\hline $\mathbf{5}$ & $\boldsymbol{F}$ & Centrifugal force & $\mathrm{MLT}^{-2}$ & $\mathrm{~kg} \cdot \mathrm{m} / \mathrm{s}^{2}$ \\
\hline $\mathbf{6}$ & $\boldsymbol{n}$ & $\begin{array}{c}\text { Number of fins per perimeter } \\
\text { of peeling chamber }\end{array}$ & $\mathrm{L}^{-1}$ & $\mathrm{~m}^{-1}$ \\
\hline
\end{tabular}

The following dimensionless groups obtained:

$$
P i_{1}=\eta_{p} \quad, \quad P i_{2}=F / P . N . V^{1 / 3} \quad \text { and } P i_{3}=n . V^{1 / 3}
$$

the following functional form is suggested:

$$
\eta_{p}=f\left(F / P N V^{1 / 3}, n V^{1 / 3}\right)
$$


The following measurements were carried out for determining the proportional constants of the dimensional analysis.

- Centrifugal force " $F$ ":

$$
F=m_{c} v^{2} / r
$$

where: $\boldsymbol{m}_{\boldsymbol{c}}$ : mass of one clove $(\mathrm{kg}), \boldsymbol{v}^{2}:$ the linear speed of disk $(\mathrm{m} / \mathrm{s})$ and $r$ :radius of disk $(\mathrm{m})$.

- Volume of sample " $V$ ":

$$
V=m / \rho_{b}
$$

where: $\boldsymbol{m}$ : mass of sample $(\mathrm{kg})$ and $\boldsymbol{\rho}_{\boldsymbol{b}}$ : bulk density $\left(\mathrm{kg} / \mathrm{m}^{3}\right)$.

\section{-Cost analysis:}

The peeling prototype hourly costs were calculated based on the fixed and variable costs of prototype by using the following formula (Awady et al., 2003):

$$
C=\frac{P_{c}}{h}\left(\frac{1}{a}+\frac{i}{2}+t+r\right)+(W . e)+\frac{m}{100}
$$

were:

$C$ = peeling prototype hourly cost, L.E. /h.

$P_{c}=$ Price of prototype, L.E., the fixed costs were 600 L.E.

$h=$ Yearly working hours, which were is assumed $1200 \mathrm{~h} /$ year

$a=$ Life expectancy of machine, about (10 Year).

$i=$ Interest rate/Year. (The bank interest in Egypt), which was about $14 \%$.

$t=$ Taxes and overheads ratio, which is assumed $20 \%$.

$r=$ Repair and maintenance ratio, which is assumed $10 \%$.

$W=$ Power $(\mathrm{kW})=(E \cdot I \cdot \mu \cdot \cos \varnothing)$.

Were: E: Potential difference (volt), I: current strength (ampere), $\mu$ :mechanical efficiency of motor (0.9) and $\cos \emptyset$ : power factor $(0.8)$.

$e=$ Hourly cost/kW.h, (0.4 L.E./kW.h).

$m=$ The monthly average wage, L.E., (600 L.E).

$100=$ The monthly average working hours.

$$
\operatorname{Cost}(L . E / \mathrm{kg})=\frac{\text { prototype hourly } \cos t(\mathrm{~L} . \mathrm{E} / \mathrm{h})}{\text { Peeling productivity }(\mathrm{kg} / \mathrm{h})}
$$

Dollar exchange rate at the time was the equivalent of 17.7 L.E. 


\section{3-RESULTS AND DISCUSSION}

\subsection{Physical properties of garlic cloves:}

Table (2) indicated that the garlic clove length, width, thickness, geometric diameter, arithmetic diameter, flat surface area and mass of one clove ranges of sample were $18.85-38.00$ (avg. $28.50 \mathrm{~mm}$ ), $7.40-14.65$ (ave. 10.70mm), $7.90-19.00$ (avg. 13.31mm), $10.30-21.88$ (avg. $15.91 \mathrm{~mm}$ ), 11.38 - 23.88 (avg. 17.25mm), 109.56 - 437.23 (avg. $245.13 \mathrm{~mm}$ ) and $0.80-3.7$ (avg. 1.9 g) respectively for "RG" garlic and 16.85 - 33.75 (avg. 23.70mm), 7.10 - 27.30 (avg. $11.50 \mathrm{~mm}$ ), $5.55-$ 12.65 (avg. 8.9mm), $9.01-19.44$ (avg. 13.30mm), $10.18-21.48$ (avg. $14.70 \mathrm{~mm}$ ), $97.86-582.13$ (ave. $245.13 \mathrm{~mm}$ ) and $0.50-3.5$ (avg. $1.2 \mathrm{~g}$ ) respectively for "WG" garlic. The average bulk density of cloves, peel percentage, clove moisture content and peel moisture content was 0.61 $\left(\mathrm{g} / \mathrm{cm}^{3}\right), 23.30(\%), 71.49$ w.b (\%) and 44.71w.b (\%) respectively for "RG" garlic and $0.64\left(\mathrm{~g} / \mathrm{cm}^{3}\right), 14.80(\%), 71.30$ w.b (\%) and 41.15 w.b (\%) respectively for "WG" garlic.

Table (2): Physical properties of two varieties garlic cloves.

\begin{tabular}{|c|c|c|c|c|c|c|c|c|}
\hline \multirow[t]{2}{*}{ Property } & \multicolumn{4}{|c|}{ Garlic cloves "RG" } & \multicolumn{4}{|c|}{ Garlic cloves "WG" } \\
\hline & Max. & Min. & Avg. & S.D & Max. & Min. & Avg. & S.D \\
\hline Length (mm) & 38.00 & 18.85 & 28.50 & 4.62 & 33.75 & 16.85 & 23.7 & 3.98 \\
\hline Width (mm) & 14.65 & 7.40 & 10.70 & 1.50 & 27.30 & 7.10 & 11.5 & 2.76 \\
\hline Thickness (mm) & 19.00 & 7.90 & 13.31 & 1.97 & 12.65 & 5.55 & 8.9 & 1.51 \\
\hline Geometric diameter (mm) & 21.88 & 10.30 & 15.91 & 2.37 & 19.44 & 9.01 & 13.3 & 1.85 \\
\hline Arithmetic diameter (mm) & 23.88 & 11.38 & 17.52 & 2.68 & 21.48 & 10.18 & 14.7 & 2.09 \\
\hline Flat surface area $\left(\mathrm{mm}^{2}\right)$ & 437.23 & 109.56 & 245.13 & 73.37 & 582.13 & 97.89 & 218.8 & 77.51 \\
\hline Mass of one clove (g) & 3.70 & 0.80 & 1.90 & 0.65 & 3.50 & 0.50 & 1.2 & 0.55 \\
\hline Mass of 100 - cloves $(\mathrm{g})$ & \multirow{5}{*}{ Avg. } & \multicolumn{3}{|c|}{190} & \multirow{5}{*}{ Avg. } & \multicolumn{3}{|c|}{1.2} \\
\hline Bulk density $\left(\mathrm{g} / \mathrm{cm}^{3}\right)$ & & \multicolumn{3}{|c|}{0.61} & & \multicolumn{3}{|c|}{0.64} \\
\hline Peel percentage $(\%)$ & & \multicolumn{3}{|c|}{23.30} & & \multicolumn{3}{|c|}{14.80} \\
\hline Clove moisture content $(\%)$ & & \multicolumn{3}{|c|}{71.49 w.b } & & \multicolumn{3}{|c|}{$71.30 \mathrm{w} . \mathrm{b}$} \\
\hline Peel moisture content $(\%)$ & & \multicolumn{3}{|c|}{44.71 w.b } & & \multicolumn{3}{|c|}{41.15 w.b } \\
\hline
\end{tabular}


3.2. Effect of the disk speed and number of fins on the peeling prototype productivity "P" (kg/h):

Fig. (4) and (5) show the relationship between peeling prototype productivity " $P$ " and disk speed " $N "$ " (1600, 1800 and 1400 r.p.m) at different number of fins (1, 2 and 3 fin) for "RG" and " WG" garlic variety.

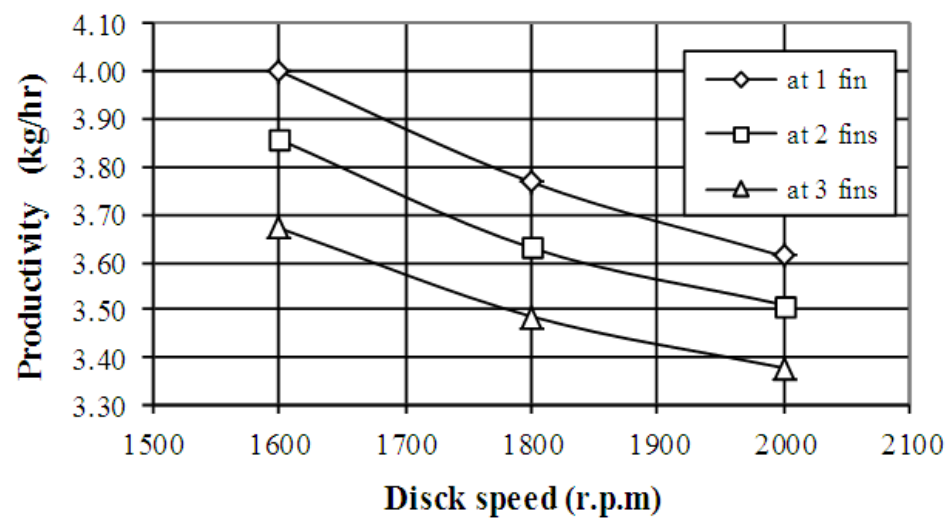

Fig. (4): The relationship between productivity of garlic peeld and disck speed at different number of fins for "RG" garlic.

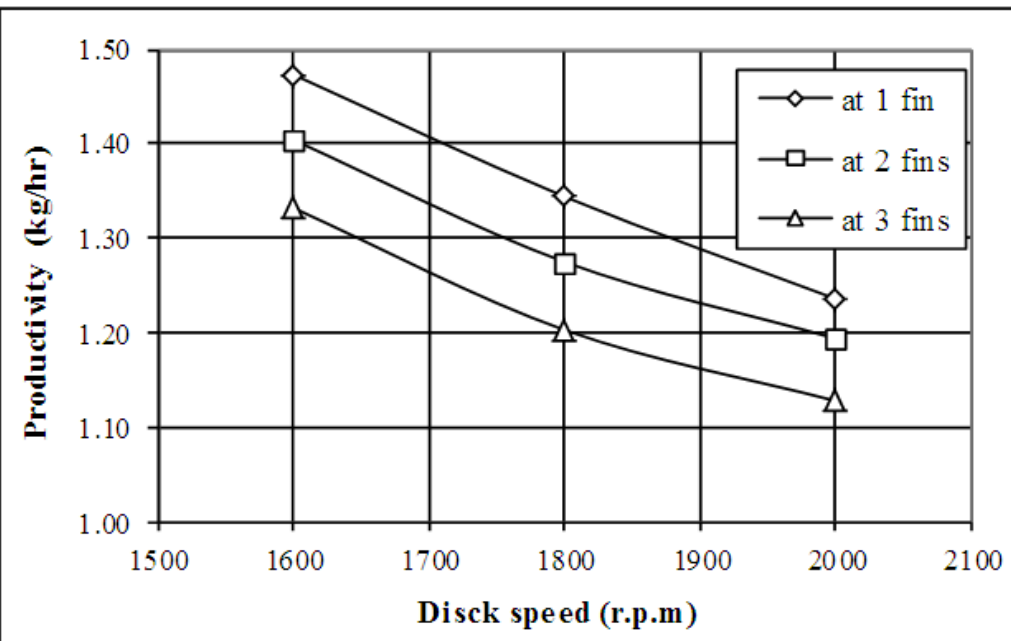

Fig. (5):The relationship be tween productivity of garlic peeld and dis ck speed at different number of fins for "WG" garlic. 
It is clear that the all curves have the same trends for all experiments. These data showed that the productivity affected inversely by increasing the disk speed and number of fins. It is clear from figs. (4)and (5) that the highest values of productivity were 4.00 and $1.47 \mathrm{~kg} / \mathrm{h}$ for "RG" and "WG" garlic respectively at disk speed of 1600 r.p.m and number of fins of 1 fin.

The productivity, when "RG" garlic used is 2.7 times that of "WG" at the same operating conditions. Therefore, prototype productivity is optimal when peeling "RG" garlic.

\subsection{Effect of the disk speed and number of fins on the peeling efficiency " $\eta_{p}$ " (\%):}

Figs. (6) and (7) show the relationship between peeling efficiency " $\eta_{p} "$ and disk speed " $N$ " (1600, 1800 and 1400 r.p.m) at different number of fins (1, 2 and 3 fin) for "RG" and "WG" garlic variety. Generally, it can be observed that the peeling efficiency increases with decreasing disk speed and number of fins. As previous result of productivity, disk speed of 1600 r.p.m and fins number of 1 fin was the optimal for the peeling prototype efficiency. Comparing peeling efficiency for the same operational conditions clear that the peeling efficiency for "RG" garlic was $85.1 \%$ compared to $57.6 \%$ for "WG" garlic, and can concluded that the peeling efficiency for "RG" garlic is higher by $27.5 \%$ than that of "WG" garlic.

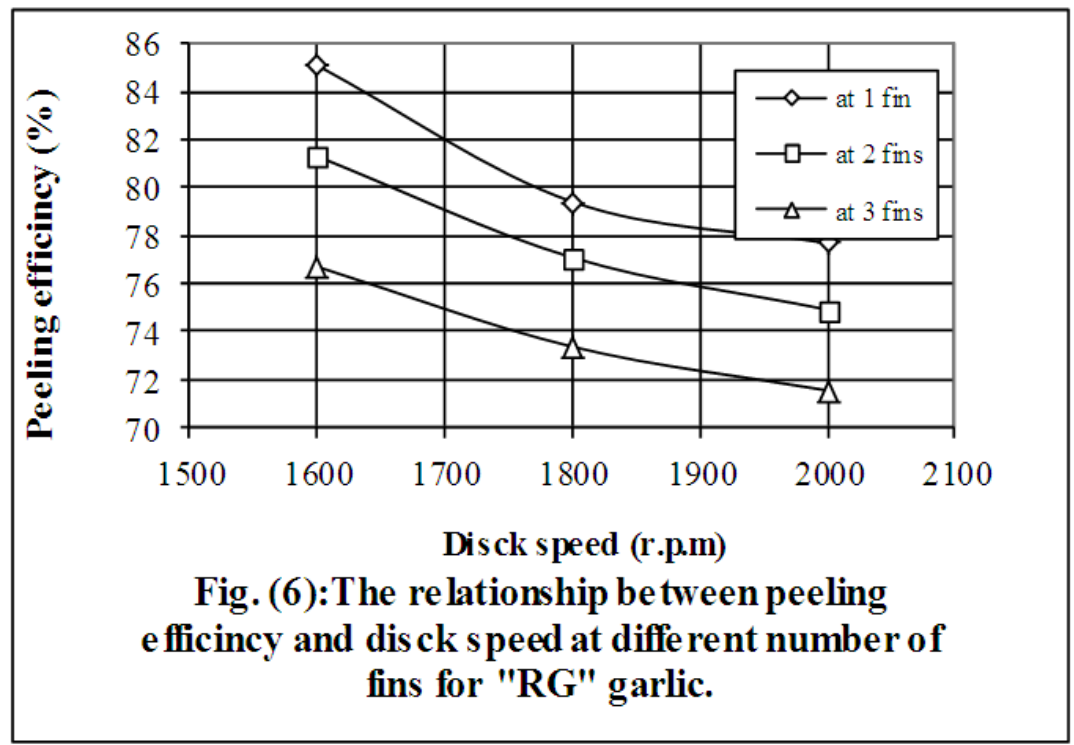




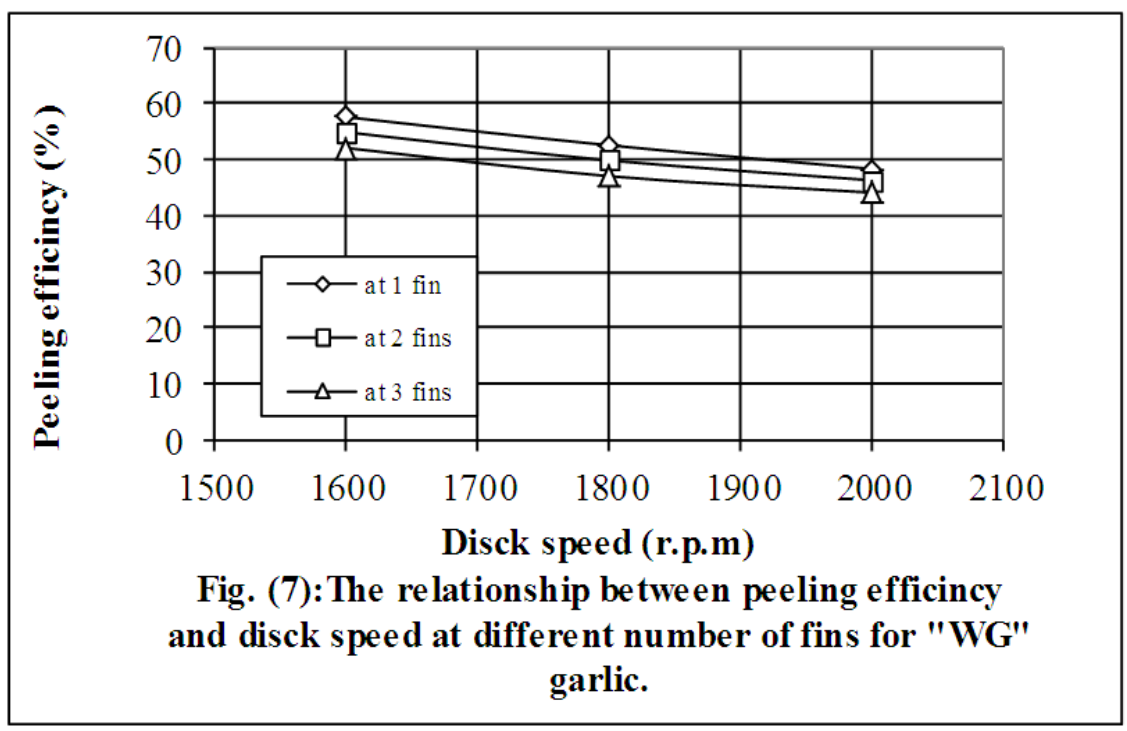

3.4. Effect of the disk speed and number of fins on damaged cloves percentage " $D_{c}$ " (\%):

Figs. (8) and (9) show the relationship between cloves damage percentage " $D_{c}$ " and disk speed " $N$ " (1600, 1800 and 1400 r.p.m) at different number of fins (1, 2 and 3 fin) for "RG" and "WG" garlic variety. Results showed that the cloves damage percentage increases proportionally with increasing disk speed, while the cloves damage percentage decreases with increasing number of fins.

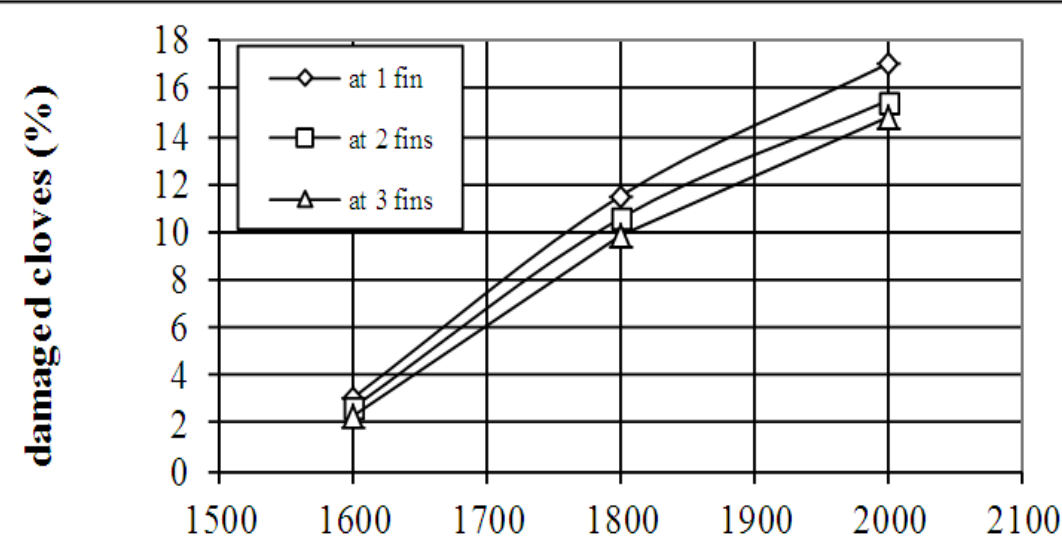

Disck speed (r.p.m)

Fig. (8): The relationship between damaged garlic cloves (\%) and disck speed at different number of fins for "RG" garlic. 


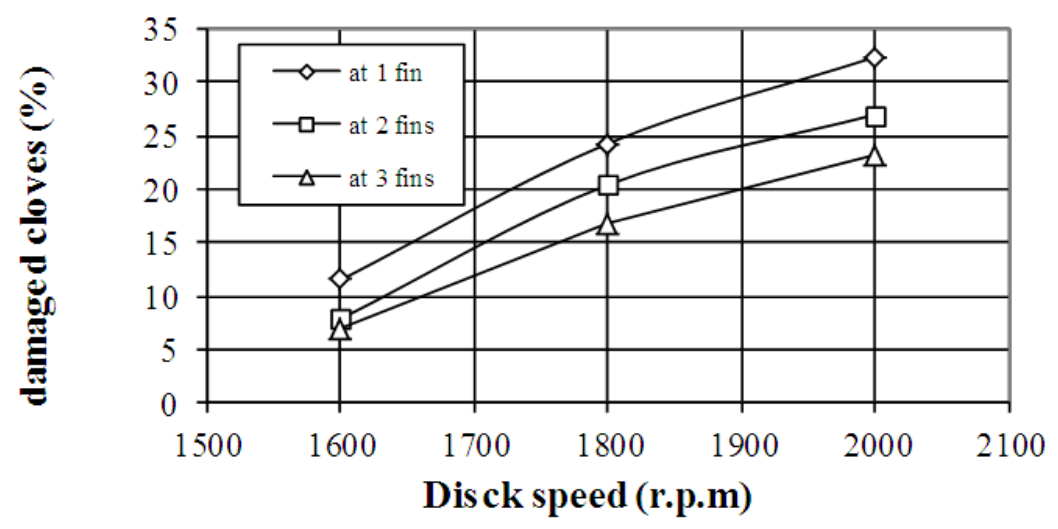

Fig. (9): The relationship between damaged garlic cloves (\%) and disck speed at different number of fins for "WG" garlic.

The lowest values of cloves damage percentage were $2.26 \%$ and $6.92 \%$ for "RG" and "WG" garlic respectively for disk speed of 1600 r.p.m and fins number of 3 fin, while the highest values of cloves damage percentage were $17.00 \%$ and $32.4 \%$ for "RG" and "WG" garlic respectively for disk speed of 2000 r.p.m and fins number of 1fin, it can also be concluded that the cloves damage percentage for "RG" garlic is lower by $4.66-15.40 \%$ than that of "WG" garlic.

\subsection{Effect of the disk speed and number of fins on unpeeled cloves percentage " $U_{c}$ " $(\%)$ :}

Figs. (10) and (11) show the relationship between unpeeled cloves percentage $" U_{c}$ " and disk speed " $N "$ (1600, 1800 and 1400 r.p.m) at different number of fins (1, 2 and 3 fin) for "RG" and " WG" garlic variety. It is clear that the unpeeled cloves percentage decreases with increasing disk speed and increases with increasing number of fins. The lowest values of unpeeled cloves percentage were $5.29 \%$ and $19.20 \%$ for "RG" and "WG" garlic respectively for disk speed of 2000 r.p.m and fins number of 1 fin, while the highest values of unpeeled cloves percentage were $21.10 \%$ and $41.00 \%$ for "RG" and "WG" garlic respectively for disk speed of 1600 r.p.m and fins number of 3fin, it can also be concluded that the unpeeled cloves percentage for "RG" garlic is lower by $14.00-$ $19.90 \%$ than that of "WG" garlic. 

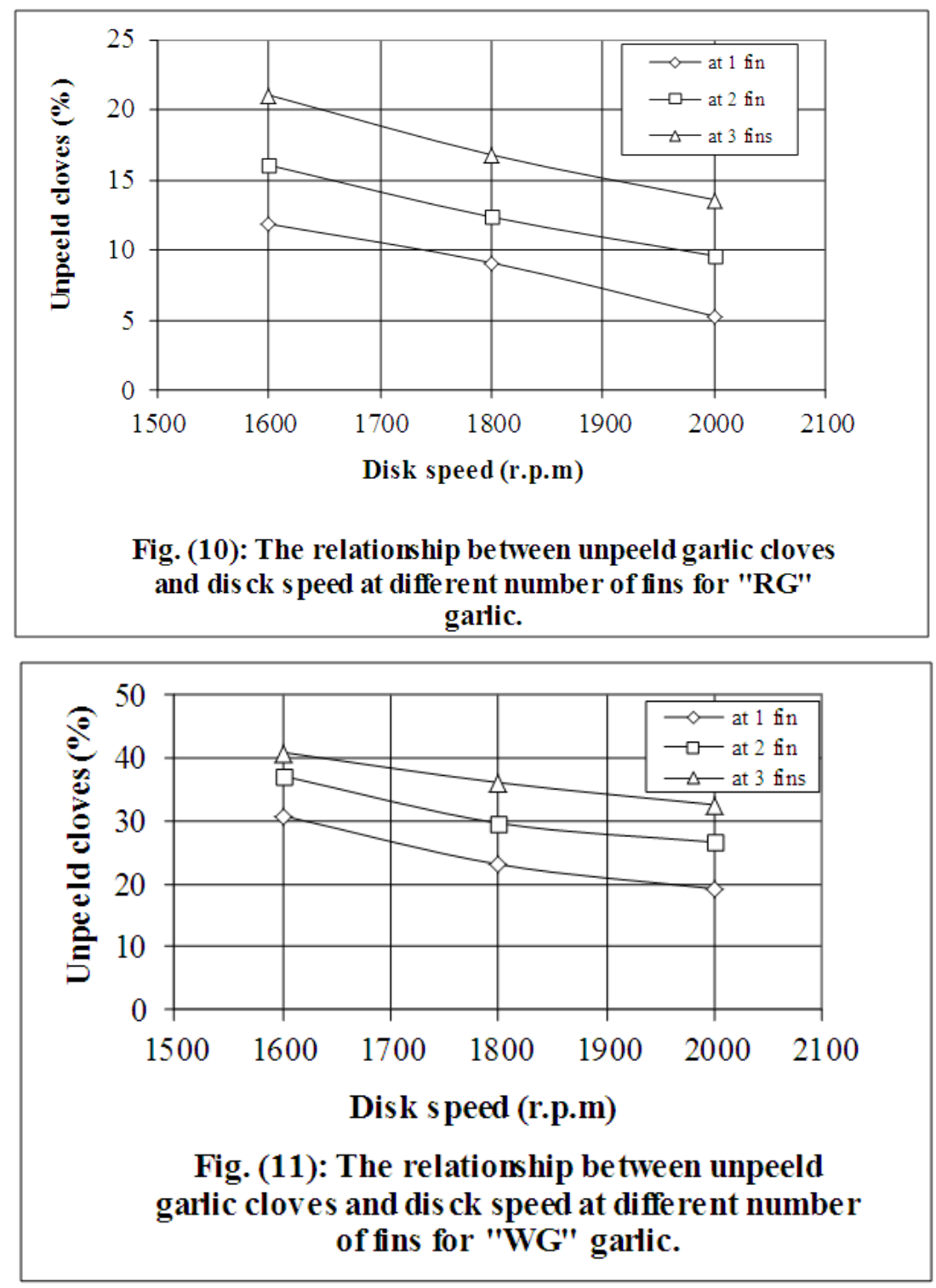

\subsection{Dimensional analysis:}

In the present study a mathematical model is developed for the peeling prototype used for peeling of garlic cloves, which can be helpful in design and operation criterion and for increasing the efficiency of research accomplishment. From previous results, it can be revealed that the peeling prototype was suitable for peeling "RG" garlic, so, the following analysis is derived. 
Chapter (2) shows that the following prediction (Pi) groups or terms are valid for peeling of "RG" garlic cloves:

$$
\eta_{p}=f\left(F / P N V^{1 / 3}, n V^{1 / 3}\right)
$$

Fig. (12) shows the relationship between $P i_{l=}\left(\eta^{p}\right)$ and $P i_{2}=\left(F / P N V^{l / 3}\right)$ when $\pi_{3}=\left(n V^{1 / 3}\right)$ varied satisfied a power function of the form:

$$
\eta_{p}=a\left(F / P N V^{1 / 3}\right)^{-b}
$$

Figs (13) and (14) show that the best fit relation of the parameter " $a$ " and " $b$ " as affected by $P i_{3}=\left(n . V^{1 / 3}\right)$ for "RG" garlic were power function of the form:

$$
a=c\left(P i_{3}\right)^{-d} \quad \text { and } \quad b=c_{1}\left(P i_{3}\right)^{-d l}
$$
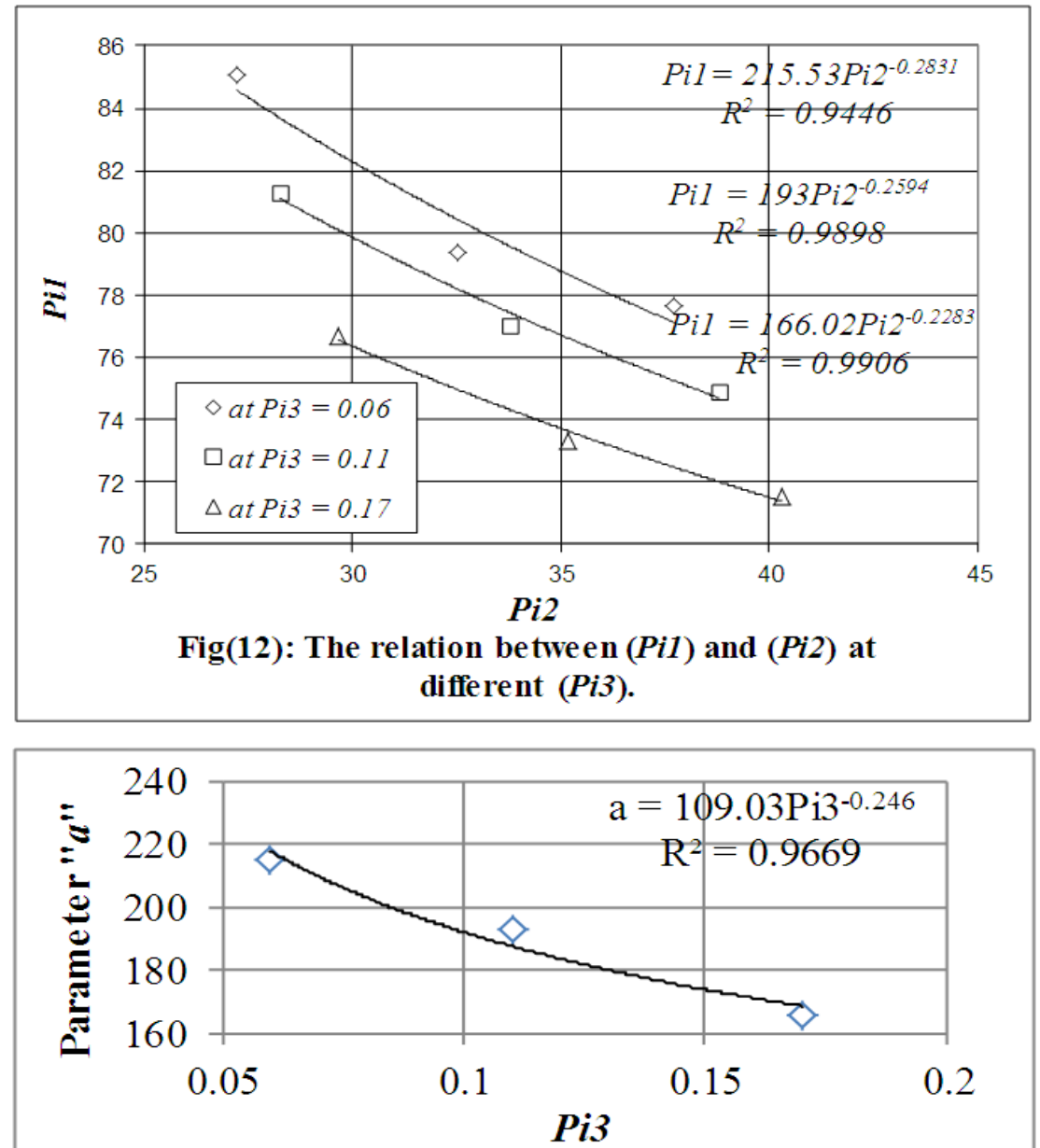

Fig. (13): The relationship between parameter " $a$ " and "Pi3". 


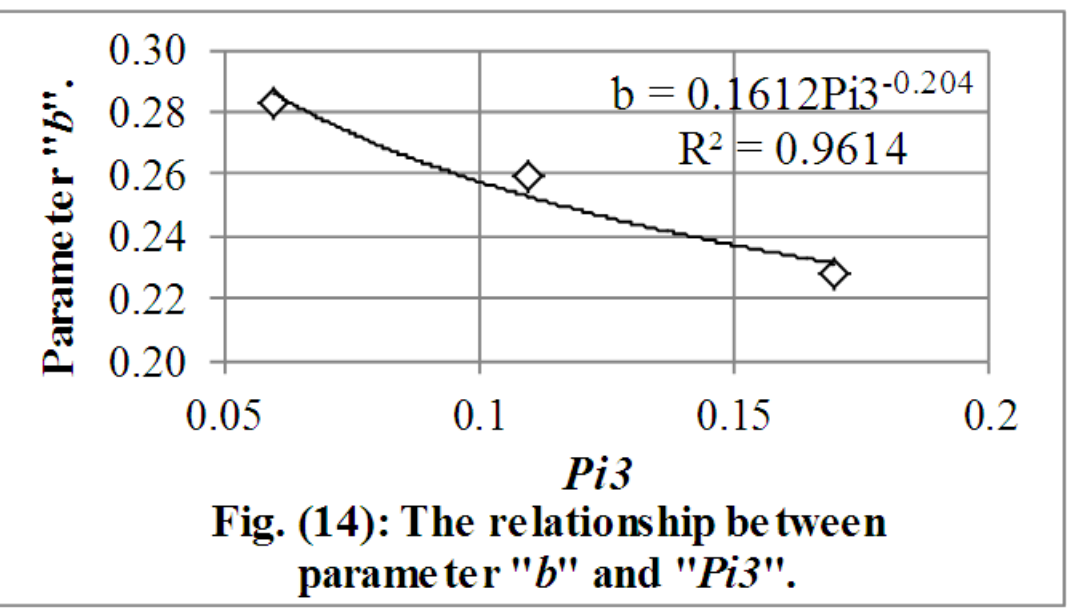

The complete prediction equation regarding the collected data of this study for peeling of "RG" garlic:

$$
\eta_{p}=109.03\left(n . V^{1 / 3}\right)^{-0.246} \times\left(\frac{F}{P N V^{1 / 3}}\right)^{-0.161\left(n . V^{1 / 3}\right)^{-0.204}} \quad \mathbf{R}^{\mathbf{2}}=\mathbf{0 . 9 7 8}
$$

Fig. (15) shows the relationship of the predicted and observed peeling efficiency for "RG" garlic.

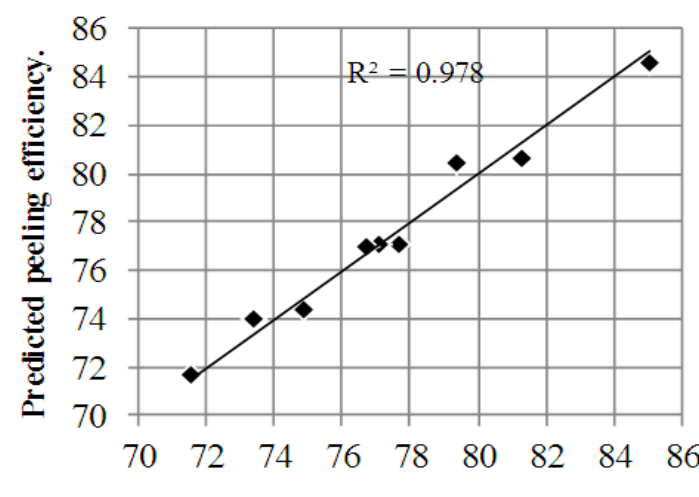

Obs erved peeling efficiency.

Fig. (15): Predicted and obs erved peeling efficiency of the prototype.

3.7. Effect of the disk speed and number of fins on the peeling cost $(\mathrm{L} . \mathrm{E} / \mathrm{kg})$ : Table (3) shows the relation between criterion cost and disk speed at different number of fins for "RG" garlic cloves. Generally, the criterion cost increases with increasing disk speed and fins number. The lowest 
criterion cost was 1.58 L.E $/ \mathrm{kg}$ at disk speed 1600 r.p.m and one fin, while the highest criterion cost was 1.88 L.E/kg at disk speed 2000 r.p.m and two fin.

Table (3): Criterion cost at different disk speed and different fins number for "RG" garlic cloves of peeling prototype.

\begin{tabular}{|c|c|c|c|}
\hline \multirow{2}{*}{$\begin{array}{l}\text { Disk speed } \\
\text { (r.p.m) }\end{array}$} & \multicolumn{3}{|c|}{ Criterion cost (L.E/kg peeld garlic) } \\
\cline { 2 - 4 } & One fin & Two fins & Tree fins \\
\hline $\mathbf{1 6 0 0}$ & 1.58 & 1.63 & 1.71 \\
\hline $\mathbf{1 8 0 0}$ & 1.68 & 1.75 & 1.82 \\
\hline $\mathbf{2 0 0 0}$ & 1.76 & 1.81 & 1.88 \\
\hline
\end{tabular}

\section{4- CONCLUSION}

The main objective of the present work is to fabricate, test and model a suitable prototype for peeling of garlic cloves raw material using dimensional analysis for the optimal selected peeling machine with the aid of productivity, peeling efficiency, cloves damage (\%), unpeeled cloves $(\%)$ and criterion cost.

Experiments were carried out with three numbers of fins (one fin, two fins and three fins) and three rotating disk speed (1600, 1800 and 2000 r.p.m) with "RG" and "WG" garlic cloves.

\section{The results can be summarized as follow:}

1- The highest values of productivity were 4.00 and $1.47 \mathrm{~kg} / \mathrm{h}$ for "RG" and "WG" garlic respectively at disk speed of 1600 r.p.m and number of fins of 1 fin.

2- The highest values of peeling efficiency were $85.1 \%$ and $57.6 \%$ for for "RG" and "WG" garlic respectively at disk speed of 1600 r.p.m and number of fins of 1 fin.

3-The lowest values of cloves damage percentage were $2.26 \%$ and 6.92 $\%$ for "RG" and "WG" garlic respectively for disk speed of 1600 r.p.m and fins number of 3 fin.

4-The lowest values of unpeeled cloves percentage were $5.29 \%$ and $19.20 \%$ for "RG" and "WG" garlic respectively for disk speed of 2000 r.p.m and fins number of 1 fin. 
5-The dimensional analysis was reasonably accepted for predicting the peeling efficiency with coefficient of determination 0.978 , that helps in producing large scale peeling machines of garlic cloves.

The complete prediction equation regarding the collected data of this study for peeling of "RG" garlic:

$$
\eta_{p}=109.03\left(n \cdot V^{1 / 3}\right)^{-0.246} \times\left(\frac{F}{P N V^{1 / 3}}\right)^{-0.161\left(n . V^{1 / 3}\right)^{-0.204}} \quad \mathbf{R}^{\mathbf{2}=\mathbf{0 . 9 7 8}}
$$

6-The lowest criterion cost was 1.58 L.E/kg at disk speed 1600 r.p.m and one fin, while the highest criterion cost was $1.88 \mathrm{~L} . \mathrm{E} / \mathrm{kg}$ at disk speed 2000 r.p.m and two fin.

\section{5-REFERENCES}

ASAE, (1994). ASAE standards. American Society of Agricultural Engineers. St. Joseph USA.

Awady, M. N.; I. Yehia; M. T. Ebaid and E. M. Arif (2003). Development and threory of rice cleaner for reduced impurities and losses. Misr J. Ag. Eng., 20 (4): 53- 68.

Emadi, B.; M. H Abbaspour-Fard and P. K. D. Yarlagadda (2007). An innovative mechanical peeling method of vegetables. Proceedings of the International Agricultural Engineering Conference, Bangkok, Thailand, 3-6 December 2007.

Langhaar, H. L., (1951). Dimensional analysis and theory of models, John Wiley and Sons, INC.

Matthews, J., ( 1991) Progress in Agricultural physics and Engineering. (Hand Book). Chapter (8): 203-227.

Mudgal, V. D. and P. S. Champawat (2011). Development of a Garlic Clove Peeler for Small Scale Industry, International Journal of Food Engineering: Vol. 7: Iss.3, Article 4.

Park, W. P.; S. H. Cho and D. S. Lee (1998). Effect of Minimal Processing operations on the quality of garlic, green onion, soybean sprouts and watercress. J. Sci. Food Agric., 77, 282-286.

Somsen, D.; A. Capelle and J. Tramper (2004). Manufacturing of parfried French-fries. Part 2: Modelling yield efficiency of peeling. Journal of Food Engineering. 61: 2, 199-207. 
Zeng, T.; F.F. Guo; C.L. Zhang; S. Zhao; D.D. Dou; X.C. Gao and K.Q. Xie (2008. ) The anqti-fatty liver effects of garlic oil on acute ethanol-exposed mice" Chemico-Biological Interactions. 176: 234242.

\section{الملخص العربيى \\ تطوير وتقييم نموذج لتقشير الثوم \\ محمد محمد إبر اهيم بلرر}

تهدف هذه الدراسة إلى إمكانية تصنيع نموذج أولى لتقشير فصوص الثوم للإستخدام المنزلى أو الو التهار

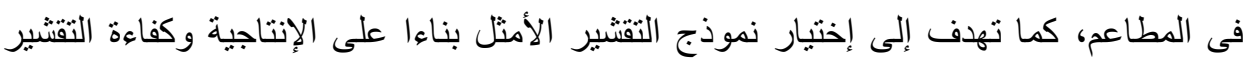

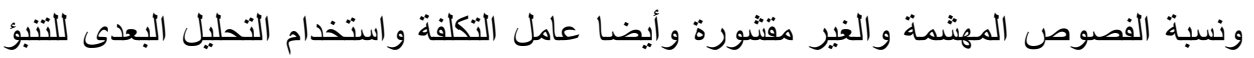

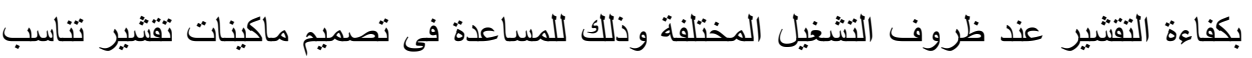

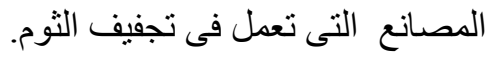

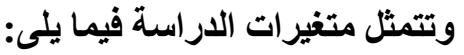

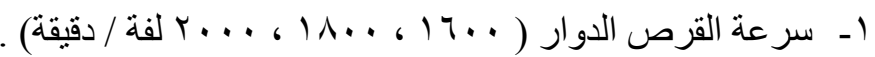

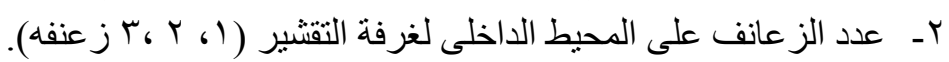

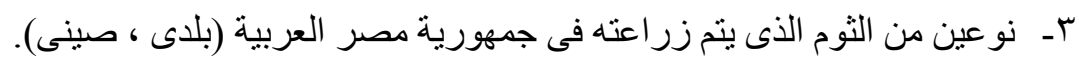

وقد تم تلخيص نتائج هذه الاراسة كالأتى:

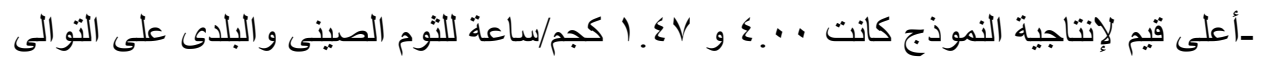

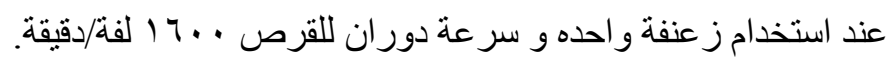

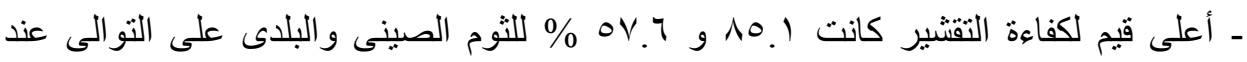

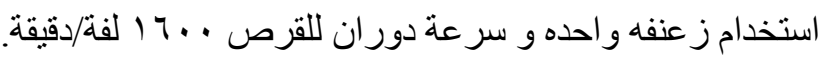

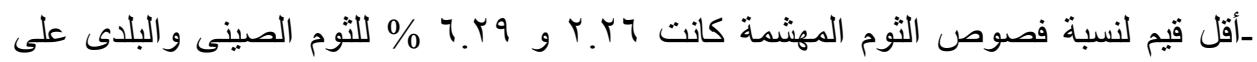

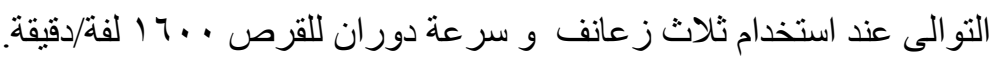

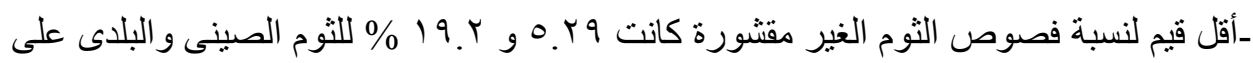

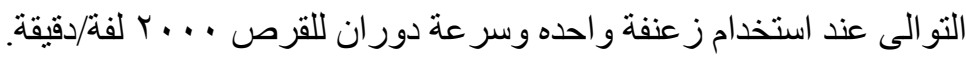

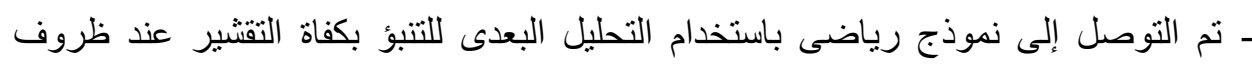

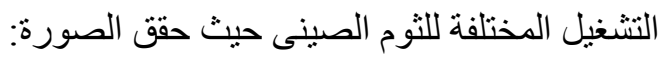
$\eta_{p}=109.03\left(n . V^{1 / 3}\right)^{-0.246} \times\left(\frac{F}{P N V^{1 / 3}}\right)^{-0.161\left(n . V^{1 / 3}\right)^{-0.204}} \quad \mathbf{R}^{2}=\mathbf{0 . 9 7 8}$

* مدرس بقسم هندسة تصنيع المنتجات الزراعية ـ كلية الهندسة الزراعيةـ جامعة الأزهر- القاهرة 